\title{
Estilos Parentais e Desenvolvimento de Habilidades Sociais na Adolescência ${ }^{1}$
}

\author{
Janaína T. B. Pacheco, Marco A. P. Teixeira e William B. Gomes² \\ Universidade Federal do Rio Grande do Sul
}

\begin{abstract}
RESUMO - Este estudo examinou a relação entre estilos parentais e o desenvolvimento de habilidades sociais na adolescência. Os sujeitos foram 193 adolescentes secundaristas de duas escolas públicas de Porto Alegre. Foram utilizados um questionário para o levantamento da percepção de desempenho em dez habilidades sociais e duas escalas (Responsividade e Exigência) para a classificação dos estilos parentais em quatro categorias: autoritário; autoritativo; indulgente e negligente. Os resultados indicaram que, de uma forma geral, os adolescentes relatam apresentar as habilidades sociais necessárias às situações investigadas. As habilidades que apresentaram maiores dificuldades foram iniciar relacionamento interpessoal; solicitar mudança no comportamento do outro e expressar sentimentos. Não foram encontradas diferenças (MANOVA) quanto à presença de habilidades sociais entre os adolescentes que identificaram seus pais em diferentes estilos parentais. No entanto, foram encontradas entre esses grupos diferenças significativas quanto às variáveis que estão relacionadas às habilidades sociais, como ansiedade e agressividade.
\end{abstract}

Palavras-chave: estilos parentais; habilidade social; adolescência.

\section{Parenting Styles and Development of Social Skills During Adolescence}

\begin{abstract}
The purpose of this study was to examine the relationship between parenting styles and development of social skills during adolescence. A total of 193 high school students (ages 14-17) from two public schools in Porto Alegre answered a questionnaire to evaluate perception of performance in ten social skills, as well as, two scales (Responsiveness and Demandingness) allowing to classify parental attitudes in four types: authoritarian, authoritative, indulgent and negligent. Generally, the results indicate that the adolescents have the necessary social skills for the investigated situations. The skills for which they presented more difficulties were the following: beginning interpersonal relationship; asking for change on someone else's behavior and expressing feelings. Significant differences on the presence of social skills among the adolescents who identified their parents according to different parenting styles were not found. However, significant differences on variables related to social skills, as anxiety and aggressiveness, were noticed among these groups.
\end{abstract}

Key words: parenting styles; social skill; adolescence.

Este estudo analisa as possíveis relações entre dois conceitos relacionados ao desenvolvimento psicológico: estilos parentais e habilidades sociais. Estilo parental é uma classificação de práticas familiares proposta por Baumrind (1966), posteriormente ampliada por pesquisadores em desenvolvimento psicológico (Lamborn, Mounts, Steinberg \& Dornbusch, 1991). O interesse por habilidades sociais surgiu a partir de trabalhos orientados por investigadores das teorias de aprendizagem (McFall, 1982). Atualmente, o conceito vem sendo utilizado e estudado nos principais campos de aplicação da psicologia (Guarch, 1994).

O estilo parental caracteriza a forma como os pais lidam com as questões de poder e hierarquia na relação com os

1 Uma versão ampliada deste trabalho foi apresentado como Dissertação de Mestrado no Curso de Pós-Graduação em Psicologia da Universidade Federal do Rio Grande do Sul pela primeira autora sob orientação do terceiro autor. A pesquisa foi realizada como apoio da CAPES e do CNPq.

2 Endereço: Instituto de Psicologia - UFRGS - Rua Ramiro Barcelos, 2600, Sala 119. CEP: 90035-003 Porto Alegre-RS. Tel. 0xx51 3165115 - Fax.: 3304797. E-mail: gomesw@ vortex.ufrgs.br filhos, e as posições que adotam frente aos problemas disciplinares, ao controle do comportamento e à tomada de decisões (Hennigen, 1994). Lamborn e cols. (1991) propuseram a utilização de escalas de responsividade e exigência para classificar os estilos parentais em quatro grandes tipos: autoritário, autoritativo ${ }^{3}$, indulgente e negligente. A dimensão responsividade refere-se às atitudes parentais que favorecem a individualidade e auto-afirmação dos filhos através do apoio e da aquiescência. Já a exigência refere-se às atitudes parentais que requeiram supervisão e disciplina, e que podem provocar confronto diante de desobediência (Maccoby \& Martin, 1983).

A combinação dessas duas dimensões é que define os quatro estilos parentais. Assim, pais com escores altos em ambas as dimensões são classificados como autoritativos; aqueles com escores baixos em ambas recebem a classificação de negligentes. Pais com escores altos em exigência, mas

3 O termo autoritativo é um neologismo usado pelos autores para traduzir o termo inglês authoritative que descreve a prática autoritária assertiva, reconhecida, competente e praticada por quem de direito. 
baixos em responsividade são denominados autoritários; por sua vez, pais com escores elevados em responsividade e baixos em exigência são classificados como indulgentes (Costa, Teixeira \& Gomes, 1998).

Segundo Glasgow, Dornbusch, Troyer, Steinberg e Ritter (1997), pais classificados como indulgentes são tolerantes e calorosos. Exercem pouca autoridade, fazem poucas exigências por comportamento maduro e permitem uma considerável auto-regulação por parte dos filhos. Por outro lado, pais considerados negligentes tendem a não monitorar o comportamento de seus filhos ou importar-se com seus interesses. Os pais indulgentes envolvem-se com seus filhos. Em contraste, os pais negligentes, freqüentemente estão preocupados com seus próprios problemas.

Pais classificados como autoritários tentam moldar e controlar o comportamento e atitudes de seus filhos de acordo com um padrão determinado. Eles tendem a enfatizar obediência, respeito pela autoridade e ordem. Pais autoritários também não encorajam o diálogo com seus filhos e esperam que as regras sejam seguidas sem que sejam necessárias muitas explicações. Em contraste, pais autoritativos estabelecem e fazem cumprir as regras firmemente. Eles monitoram a conduta e usam métodos não punitivos para disciplinar, quando as regras são violadas. Esperam e reforçam responsabilidade social e comportamento maduro em seus filhos. Pais autoritativos também são calorosos. Eles encorajam o diálogo, incentivam o ponto de vista dos filhos e reconhecem os direitos dos pais e filhos.

A tipologia dos estilos parentais foi originalmente desenvolvida para pesquisa de práticas socializadoras na família durante a infância. No entanto, o modelo também vem sendo utilizado para estudar as relações entre as atitudes parentais e vários aspectos do desenvolvimento na adolescência (Glasgow \& cols., 1997). Muitos estudos têm encontrado associações importantes entre os estilos parentais e o desempenho dos adolescentes em diversas áreas, tais como desempenho acadêmico, competência psicossocial, bem-estar e ajustamento psicológico (Dornbusch, Ritter, Leiderman, Roberts \& Fraleigh, 1987; Glasgow \& cols.; Hennigen, 1994; Steinberg, Elmen \& Mounts, 1989). Na maioria dos trabalhos, os adolescentes que percebem seus pais como autoritativos têm obtido melhor desempenho em praticamente todas as áreas.

As habilidades sociais referem-se a comportamentos individuais e contextualizados em relações interpessoais que comunicam sentimentos, atitudes, expectativas, opiniões e direitos de modo adequado à situação, respeitando esta mesma possibilidade de expressão nos interlocutores. O domínio das habilidades sociais contribui para a resolução dos problemas imediatos da situação e a redução da probabilidade de futuros problemas. As habilidades sociais são aprendidas ao longo do desenvolvimento e são fundamentais para que o indivíduo estabeleça relações adequadas com o ambiente (Caballo, 1993; Hidalgo \& Abarca, 1994; Rojas, 1995). Devem ser avaliadas dentro de um marco cultural determinado e dos padrões de comunicação que variam amplamente entre culturas e dentro de uma mesma cultura, dependendo de fatores tais como idade, sexo, classe social e educa- ção. A conduta considerada apropriada em uma situação pode ser obviamente inapropriada em outra. Além disso, as peculiaridades de cada contexto social (cultura, valores, papéis, normas) irão propiciar determinados padrões de comportamento, guardando uma característica idiossincrática para cada indivíduo e grupo social (Caballo, 1993).

As habilidades sociais podem ser analisadas em níveis molares e moleculares. Os níveis molares referem-se às classes funcionais mais amplas de ações e reações dos indivíduos, por exemplo, fazer pedidos, iniciar e manter conversação e expressar desagrado. Os níveis moleculares são definidos como as partes dessas ações, ou seja, os aspectos verbais (conteúdo da fala, uso de perguntas, uso de expressões particulares, etc.), os não verbais (contato visual, postura, meneios da cabeça, gesticulação, etc.), os paralingüísticos (volume da voz, entonação, velocidade, clareza, etc.) e os mistos (autoridade/liderança, humor/formalidade, afetividade, etc.). As características moleculares são importantes, pois precisam ser coerentes para dar consistência à mensagem e alcançar os efeitos pretendidos sobre o interlocutor (Del Prette, Del Prette, Torres \& Pontes, 1998; Guarch, 1994). Exemplos de comportamentos reconhecidos e estudados como habilidades sociais são:

Iniciar e manter conversações; falar em público; expressões de amor, agrado e afeto; defender os próprios direitos; pedir favores; recusar pedidos; fazer obrigações; aceitar elogios; expressar opiniões pessoais, inclusive as discordantes; expressar incômodo, desagrado ou enfado; desculpar-se ou admitir ignorância; pedir mudança no comportamento do outro; enfrentar críticas. (Amaral, Bravo \& Messias, 1996, p. 33)

As dificuldades nas habilidades sociais são compreendidas como deficiências na aprendizagem de padrões comportamentais e cognitivos que constituem as respostas adequadas às situações (Hidalgo \& Abarca, 1994; Sarason \& Sarason,1981). Contudo, a ausência da resposta adequada não é o único indício de deficiência. A presença de ansiedade e de outros aspectos que interferem no desempenho social podem ser considerados também como indicadores de deficiência em habilidades sociais (Del Prette, Del Prette \& Castelo Branco, 1992; Trower, 1995).

O desenvolvimento das habilidades sociais ocorre primeiramente nas relações interpessoais, principalmente com a família e o grupo de pares (Arón \& Milicic, 1994). Havendo falhas neste desenvolvimento, as habilidades podem ser aprendidas fora do ambiente natural em programas específicos de treinamento (Caballo, 1993; Hidalgo \& Abarca, 1994; Rimm \& Masters, 1983; Rojas, 1995).

A importância dos pais para a aquisição de habilidades sociais tem sido demonstrada por alguns estudos. Por exemplo, o estilo familiar, o sistema de crenças, os valores e o modo como o adolescente percebe e dá significado a esses aspectos são elementos que têm impacto importante no desenvolvimento dessas habilidades (Arón \& Milicic, 1994). Por outro lado, o indivíduo tem na família a base do seu desenvolvimento social (Kaplan \& Sadock, 1991/1993; Lewis, \& Wolkmar, 1990/1993; Wagner, Flacke \& Meza, 1997). Na adolescência, as habilidades já adquiridas preci- 
sam ser integradas para que o jovem possa estabelecer relações interpessoais independentes e continuar avançando no seu desenvolvimento psicológico (Amaral, Bravo \& Messias, 1996; Hidalgo \& Abarca, 1994).

A área de maior dificuldade em habilidades sociais para adolescentes é a iniciação de relações interpessoais, por exemplo, estabelecer conduta heterossexual, participar e integrar-se a grupos de pares, defender seus direitos e relacionar-se com figuras de autoridade (Hidalgo \& Abarca, 1994). As autoras chilenas ressaltam, no entanto, que a grande maioria desses estudos provém de trabalhos americanos ou europeus, o que impõe limites à interpretação dos resultados.

No Brasil, poucos trabalhos têm investigado as habilidades sociais na adolescência. Esses estudos têm se preocupado em avaliar programas de treinamento para adolescentes com características específicas (Amaral e cols., 1996; Garcia \& Del Prette, 1998). Não foram encontrados estudos preocupados em investigar aspectos da relação familiar que pudessem estar envolvidos no desenvolvimento das habilidades sociais. No entanto, encontrou-se um trabalho recente (Silva \& Del Prette, 1998) interessado em avaliar um programa de treino de habilidades sociais em pais, com o objetivo de melhorar a relação com os filhos. Os resultados indicaram que o treino foi bem sucedido, havendo aumento na expressão de carinho, de atenção, de uso de reforçamento positivo, melhora na capacidade de resolução de problemas e redução no uso de punições. Contudo, persistiram dificuldades em lidar com desobediência e agressividade dos filhos. Esses dados indicam a importância de compreender as variáveis familiares que estão envolvidas no desenvolvimento de habilidades sociais, possibilitando a implementação de programas de treinamento efetivos para os pais e a prevenção de distúrbios psicossociais nos adolescentes, relacionados à deficiência no domínio das habilidades sociais.

O presente estudo concentra-se na investigação das possíveis relações entre a presença de habilidades sociais na adolescência e os estilos parentais percebidos pelos adolescentes. A integração desses dois conceitos poderá contribuir para a discussão das habilidades sociais e para a compreensão das variáveis, localizadas na relação entre pais e filhos, que influenciam o desenvolvimento de comportamento socialmente habilidoso. As perguntas de pesquisa são as seguintes: (1) Como adolescentes de nível sócio-cultural médio e baixo desempenham as habilidades sociais? (2) Quais as situações interpessoais nas quais há maior dificuldade no desempenho social, para esses adolescentes? (3) Existem diferenças entre os grupos de adolescentes que identificam seus pais com os diferentes estilos quanto à presença de habilidades sociais?

\section{Método}

\section{Sujeitos}

Foram sujeitos desse estudo 193 estudantes do $2^{\circ}$ grau de duas escolas estaduais situadas na área central de Porto Alegre e que atendem uma população de nível sócio-cultural médio e baixo. As idades variaram entre 14 e 17 anos. A média de idade dos sujeitos foi 15,8 anos, sendo 15 anos a idade mais comum $(36,6 \%)$. Quanto ao sexo, 71 sujeitos eram do sexo masculino $(36,8 \%)$ e 122 eram do sexo feminino $(63,2 \%)$. Destes jovens, $125(64,8 \%)$, portanto a maioria, eram filhos de pais que coabitam, $70(36,3 \%)$ tinham apenas um irmão, $64(33,2 \%)$ eram primogênitos. A idade média dos pais foi de 43 anos para as mães e 46 anos para os pais. Quanto à escolaridade das mães, $42,9 \%$ tinham curso superior, $41,9 \%$ curso secundário e 15,2\% curso primário. Distribuição muito próxima foi obtida na escolaridade dos pais, sendo $41,9 \%$ com curso superior, $42,9 \%$ curso secundário e $15,2 \%$ curso primário. Os adolescentes, em sua maioria, responderam a escala referindo-se a mães $(96,9 \%)$ e pais naturais $(91,2 \%)$.

\section{Instrumentos}

Foram utilizados um questionário para investigar as habilidades sociais e duas escalas para a categorização de estilos parentais. A seguir será apresentada a descrição dos instrumentos.

\section{Questionário de Habilidades Sociais}

O questionário para investigar as habilidades foi construído a partir de três referências. A primeira foi o instrumento citado por Del Prette e cols. (1992), constituído de 13 situações interpessoais. Nesse instrumento, após uma breve descrição das situações, os sujeitos deveriam responder a questões fechadas que avaliavam o grau de incidência da situação em sua experiência, o grau de incômodo diante da situação, a emissão ou não de uma resposta sugerida como reação ao(s) interlocutor(es) e a satisfação ou insatisfação com a própria resposta emitida. A segunda referência foi um estudo realizado previamente, com o objetivo de investigar quais situações interpessoais os adolescentes enfrentam em seu dia-a-dia e que impõem dificuldades para seu desempenho. Com isso, pretendia-se definir as situações que deveriam constituir o questionário utilizado. Sendo assim, as habilidades de iniciar relacionamentos interpessoais, iniciar relacionamento com sexo oposto, oferecer ajuda, recusar pedidos, falar em público, expressar opiniões diante dos pais, expressar sentimentos foram investigadas por terem sido referidas pelos adolescentes naquele estudo. Além disso, foram incluídas mais três habilidades (defender os próprios direitos, solicitar mudança no comportamento do outro, expressar opiniões em grupo de pares). Estas, embora não tenham sido referidas, são freqüentemente citadas como importantes na literatura. Finalmente, as situações propostas por Levenson e Gottman (1978) serviram como referência para o conteúdo de algumas situações usadas no questionário.

O questionário preparado para este estudo foi organizado em 10 itens, sendo cada item referente a uma determinada situação interpessoal. As habilidades sociais investigadas foram: (A) habilidades de iniciar relacionamentos interpessoais; (B) defender os próprios direitos; (C) iniciar relacionamento com sexo oposto; (D) expressar opiniões em grupo de pares; (E) solicitar mudança no comportamento do ou- 
tro; $(\mathrm{F})$ oferecer ajuda; $(\mathrm{G})$ recusar pedidos; $(\mathrm{H})$ falar em público; (I) expressar opiniões diante dos pais; e (J) expressar sentimentos. As instruções solicitavam aos sujeitos dois tipos de resposta: primeiro, que descrevessem seu comportamento em relação à situação sugerida pelo item; segundo, que classificassem sua resposta, de acordo com indicações prefixadas no questionário, quanto à freqüência de enfrentamento da situação (alta, média ou baixa), ao grau de incômodo (muito ou pouco) e ao grau de satisfação com o seu próprio desempenho (satisfeito ou insatisfeito).

A utilização deste questionário permitiu a investigação das habilidades sociais a partir do relato dos adolescentes, ou seja, da descrição que realizaram de seu comportamento, nas situações interpessoais. Dessa forma, deve-se considerar que pode haver uma diferença entre a percepção que o adolescente possui de seu comportamento e, portanto, a forma como o relata e o comportamento propriamente desempenhado.

\section{Escalas de Responsividade e Exigência Parental}

Os estilos parentais foram classificados através das Escalas de Responsividade e Exigência Parental (Lamborn, Mounts, Steinberg \& Dornbusch, 1991), adaptadas para o português por Costa, Teixeira e Gomes (1998). A Escala de Exigência é formada por 6 itens e a de Responsividade por 10, aos quais os sujeitos respondem utilizando uma escala Likert de 3 pontos, referente à freqüência com que seus pais (pais e mães avaliados separadamente) manifestam os comportamentos descritos. Os índices de consistência interna (alpha de Cronbach) obtidos para as escalas de responsividade e exigência no estudo de adaptação do instrumento foram, respectivamente, 0,81 e 0,90 , considerando-se os escores combinados de pais e mães. Na presente pesquisa, os coeficientes observados foram 0,87 e 0,83 .

\section{Procedimentos}

Os questionários foram aplicados de forma coletiva, em sala de aula, pela pesquisadora, em turmas previamente designadas pelas escolas. Na aplicação do questionário de habilidades sociais, as instruções foram lidas em voz alta pela pesquisadora, lembrando aos sujeitos que respondessem de forma discursiva como agem, o que pensam e sentem diante das situações descritas. Esclareceu-se aos sujeitos que caso nunca tivessem vivenciado a situação descrita, respondessem como provavelmente se comportariam, tendo em vista outras situações semelhantes já vivenciadas. Solicitou-se também que os sujeitos não deixassem de classificar suas respostas no espaço indicado pelo questionário. Quanto às escalas de responsividade e exigência, foi pedido aos sujeitos que respondessem objetivamente aos itens referentes a pai e mãe, sempre que possível. Só foram incluídos na amostra os sujeitos que preencheram de forma completa estas escalas.

\section{Análise dos dados}

As respostas do Questionário de Habilidades Sociais foram avaliadas e categorizadas pelos pesquisadores de acordo com padrões predefinidos quanto à adequação do com- portamento descrito (adequado ou inadequado), à presença de ansiedade (sim ou não) e à presença de comportamento agressivo (sim ou não). Desta forma, foram categorizadas como comportamento adequado aquelas respostas indicadoras de presença da habilidade requerida na situação. Como comportamento inadequado foram classificadas aquelas respostas que apresentavam conteúdo agressivo, que faltavam com a verdade (inventar mentira para resolver a situação, por exemplo) e/ou que descreviam um comportamento de esquiva da situação (por exemplo, quando o sujeito evita expor-se à situação). A presença de ansiedade e agressividade foi avaliada em função das expressões verbais usadas pelos sujeitos. Beck (conforme citado por Chioqueta, 1998) propõe um conceito no qual a ansiedade refere-se a um processo emocional que envolve uma resposta à avaliação de um estímulo como assustador, ou seja: quando uma pessoa está ansiosa, ela experiencia um estado emocional subjetivo e desagradável, caracterizado como tensão ou nervosismo, ou sintomas fisiológicos como palpitações, tremores, náuseas e/ou vertigens. Tendo por base esse conceito, foram considerados índices de ansiedade aquelas expressões utilizadas pelos sujeitos que relatassem desconforto diretamente relacionado com a situação interpessoal em questão. Por exemplo: "eu não me sentiria à vontade"; "eu fico muito envergonhada e não sei o que fazer"; "fico nervosa e com vergonha"; "me sentiria muito mal"; "fico nervosa e angustiada"; "me sinto um pouco incomodada". Por outro lado, como agressividade foram consideradas as expressões utilizadas pelos sujeitos que descrevessem comportamentos direcionados, abertamente, ao interlocutor e que objetivassem ofender, constranger, provocar briga, ameaçar ou vingar-se. Por exemplo: "eu começo a brigar com ele"; "jogo o estojo na cara, grito, falo coisas que magoam"; "faço brincadeiras desagradáveis também"; "eu boto a boca no indivíduo"; "falo uma piada irônica para que a pessoa se sinta constrangida"; "eu revido"; "armo o maior barraco"; "tento me vingar". A consistência da classificação das respostas foi posteriormente conferida com a participação de um juiz independente que categorizou $10 \%$ dos questionários, obtendo um grau de concordância com os pesquisadores de $94,9 \%$.

Os indicadores de adequação do comportamento, presença de ansiedade e agressividade, grau de incômodo e satisfação avaliados em cada situação permitiram a computação de escores médios para essas variáveis nas dez situações apresentadas. O problema de perda de casos devido a dados omissos foi minimizado através do cálculo da média para cada variável, mesmo quando havia até 3 situações para as quais não tinham sido dadas respostas. Foram criadas, então, as seguintes variáveis: índice de adequação do comportamento (variando de 1 a 2), índice de ansiedade (variando de 0 a 1 ), índice de agressividade (variando de 0 a 1 ), índice de incômodo (variando de 1 a 2) e índice de satisfação (variando de 1 a 2). Para qualquer variável, quanto maior o valor, maior a presença ou intensidade da característica a que se refere.

A combinação dos escores obtidos nas Escalas de Responsividade e Exigência foi utilizada para determinar os es- 
tilos parentais. Nesse caso, pais que apresentaram baixo nível em responsividade e alto em exigência foram classificados como autoritários; os que apresentaram alto nível nos dois aspectos foram classificados como autoritativos; pais que apresentaram alto nível em responsividade e baixo em exigência foram classificados como indulgentes; finalmente, os pais que apresentaram baixo nível tanto em responsividade quanto em exigência foram classificados como negligentes (Lamborn, Mounts, Steinberg \& Dornbusch, 1991). Os escores de pais e mães foram combinados para classificar o estilo parental do casal. Para isso foram somados os escores obtidos pelos pais e pelas mães nas dimensões exigência e responsividade. O critério utilizado para determinar se um escore era alto ou baixo foi o da mediana da amostra, a fim de minimizar a exclusão de casos quando da categorização dos estilos.

\section{Resultados}

A Tabela 1 mostra os resultados das análises descritivas das variáveis relacionadas às habilidades sociais em cada situação interpessoal investigada. As freqüências apresentadas referem-se aos percentuais válidos das respostas dadas ao questionário. Um teste de associação de variáveis (Quiquadrado) foi realizado para verificar se existia alguma relação entre a emissão de comportamento adequado e a satisfação percebida pelos sujeitos em cada situação, obtendo os seguintes resultados: (A) habilidades de iniciar relacionamentos interpessoais $\left(\chi^{2}=32,5 ; g l=1 ; p<0,05\right)$; (B) defender os próprios direitos $\left(\chi^{2}=11,7 ; g l=1 ; p<0,05\right)$; (C) iniciar relacionamento com sexo oposto $\left(\chi^{2}=34,7 ; g l=1 ; p\right.$ $<0,05)$; (D) expressar opiniões em grupo de pares $\left(\chi^{2}=4,4\right.$; $g l=1 ; p<0,05$ ); (E) solicitar mudança no comportamento do outro $\left(\chi^{2}=3,1 ; g l=1 ; p>0,05\right)$; (F) oferecer ajuda $\left(\chi^{2}=\right.$ $8,6 ; g l=1 ; p<0,05) ;(\mathrm{G})$ recusar pedidos $\left(\chi^{2}=0,04 ; g l=1\right.$; $p>0,05)$; (H) falar em público $\left(\chi^{2}=18,9 ; g l=1 ; p<0,05\right)$;
(I) expressar opiniões diante dos pais $\left(\chi^{2}=29,0 ; g l=1 ; p<\right.$ $0,05)$; e (J) expressar sentimentos $\left(\chi^{2}=16,9 ; g l=1 ; p<\right.$ $0,05)$. O teste indicou a existência de associação significativa $(p<0,05)$ para quase todas as situações, exceto solicitar mudança no comportamento do outro (E) e recusar pedidos $(\mathrm{G})$.

De uma forma geral, os adolescentes relataram apresentar as habilidades sociais requeridas nas situações, tendo em vista as frequiências de comportamentos adequados que foram encontradas. As situações que investigam as habilidades de iniciar relacionamentos interpessoais, solicitar mudança no comportamento do outro e expressar sentimentos apresentaram uma maior freqüência de comportamento inadequado $(40,2 \%, 55,5 \%, 67,7 \%$, respectivamente) indicando que podem haver deficiências nessas áreas.

A situação que exigiu habilidade de falar em público foi a que apresentou maior freqüência de ansiedade (19,2\%). Por outro lado, as situações em que se observou maior freqüência de comportamento agressivo foram aquelas nas quais foram investigadas as habilidades de defender os próprios direitos, de solicitar mudança no comportamento do outro e de expressar sentimentos. Quatro situações foram relatadas, por mais de $20 \%$ dos adolescentes, como ocorrendo com alta freqüência: iniciar relacionamento com sexo oposto; expressar opiniões em um grupo de pares; oferecer ajuda e expressar opiniões diante dos pais. Somente três situações foram avaliadas, por mais de $50 \%$ dos adolescentes, como sendo muito incômodas: defender os próprios direitos; solicitar mudança no comportamento do outro e expressar sentimentos. As situações que se referem às habilidades de recusar pedidos, falar em público e expressar opiniões diante dos pais foram referidas como muito incômodas por aproximadamente $40 \%$ dos adolescentes.

Mais de 70\% dos adolescentes relataram satisfação com seu próprio comportamento na maioria das situações (A, C, D, E, F, H, I). Somente nas situações que avaliavam as habilidades de defender os próprios direitos, expressar sentimento

Tabela 1 - Freqüências (em porcentagem) dos indicadores de adequação de resposta, presença de ansiedade e agressividade, freqüência de ocorrência, nível de satisfação e incômodo para cada situação interpessoal

\begin{tabular}{|c|c|c|c|c|c|c|c|c|c|c|c|c|c|c|}
\hline & & \multicolumn{2}{|c|}{ A dequação da resposta } & \multicolumn{2}{|c|}{$\begin{array}{l}\text { Presença de } \\
\text { ansiedade }\end{array}$} & \multicolumn{2}{|c|}{$\begin{array}{l}\text { Presença de } \\
\text { agressividade }\end{array}$} & \multicolumn{3}{|c|}{$\begin{array}{l}\text { Freqüência de } \\
\text { ocorrência }\end{array}$} & \multicolumn{2}{|c|}{$\begin{array}{c}\text { Nível de } \\
\text { incômodo }\end{array}$} & \multicolumn{2}{|c|}{ Nível de satisfação } \\
\hline & & Adequada & Inadequada & Sim & Não & Sim & Não & Alta & Média & Baixa & M uito & Pouco & Satisfeito & Insatisfeito \\
\hline $\bar{A}$ & - Iniciar relacionamentos ${ }^{* *}$ & 59,8 & 40,2 & 8,8 & 91,2 & 10,5 & 89,5 & 2,6 & 31,6 & 65,8 & 34,7 & 65,3 & 75,6 & 24,4 \\
\hline B & - Defender os próprios direitos* & 65,4 & 34,6 & 0 & 100 & 10,9 & 89,1 & 7,3 & 35,8 & 57 & 78,2 & 21,8 & 72,5 & 27,5 \\
\hline C & $\begin{array}{l}\text { - Iniciar relacionamento com sexo } \\
\text { oposto }^{* *}\end{array}$ & 82,1 & 17,9 & 1 & 99 & 0 & 100 & 23,4 & 53,6 & 22,9 & 11,5 & 88,5 & 81,8 & 18,2 \\
\hline D & $\begin{array}{l}\text { - Expressar opiniões em grupo de } \\
\text { pares }^{* *}\end{array}$ & 91,1 & 9,1 & 0 & 100 & 21 & 79 & 44 & 45,1 & 10,9 & 26,4 & 73,6 & 87 & 13 \\
\hline $\mathrm{E}$ & $\begin{array}{l}\text { - Solicita mudança no } \\
\text { comportamento do outro }\end{array}$ & 44,5 & 55,5 & 1 & 99 & 28 & 72 & 12,4 & 31,6 & 56 & 66,8 & 33,2 & 71 & 29 \\
\hline $\mathrm{F}$ & - Oferecer ajuda* & 97,9 & 2,1 & 0 & 100 & 0 & 100 & 32,6 & 49,7 & 17,6 & 34,2 & 65,8 & 91,2 & 8,8 \\
\hline G & - Recusar pedidos & 74,9 & 25,1 & 0 & 100 & 2,1 & 87,9 & 15 & 44 & 40,9 & 37,8 & 62,2 & 65,3 & 34,7 \\
\hline $\mathrm{H}$ & - Falar em público** & 65,8 & 34,2 & 19,2 & 80,8 & 0,5 & 99,5 & 5,2 & 31,1 & 63,7 & 47,9 & 52,1 & 74,5 & 25,5 \\
\hline I & $\begin{array}{l}\text { - Expressar opiniões diante dos } \\
\text { pais }^{* *}\end{array}$ & 88,8 & 11,2 & 0,5 & 99,5 & 3,6 & 96,4 & 32,1 & 47,7 & 20,2 & 44,6 & 55,4 & 80,8 & 19,2 \\
\hline J & - Expressar sentimentos ${ }^{* *}$ & 32,3 & 67,7 & 0 & 100 & 9,3 & 90,7 & 8,8 & 35,2 & 56 & 87 & 13 & 61,1 & 38,9 \\
\hline
\end{tabular}

** Teste Qui-quadrado indicou associação significativa $(p<0,05)$ entre adequação da resposta e satisfação com a mesma (e vice-versa). 
Tabela 2 - Correlações (Pearson) entre exigência e responsividade parental e os índices de resposta adequada, ansiedade, agressividade, incômodo e satisfação

\begin{tabular}{|c|c|c|c|c|c|c|}
\hline & $\begin{array}{l}\text { Exigência } \\
\text { combinada }\end{array}$ & $\begin{array}{l}\text { Responsividade } \\
\text { combinada }\end{array}$ & $\begin{array}{l}\text { Índice comp. } \\
\text { adequado }\end{array}$ & $\begin{array}{l}\text { Índice de } \\
\text { incômodo }\end{array}$ & $\begin{array}{l}\text { Índice de } \\
\text { satisfação }\end{array}$ & $\begin{array}{c}\text { Índice de } \\
\text { agressividade }\end{array}$ \\
\hline Responsividade combinada & $0,5485^{*}$ & & & & & \\
\hline Índice comportamento adequado & $0,1294-$ & 0,0607 & & & & \\
\hline Índice de incômodo & $-0,1775^{*}$ & $-0,1864 *$ & $-0,1480 *$ & & & \\
\hline Índice de satisfação & 0,2009* & $0,1707^{*}$ & $0,1794 *$ & $-0,3821 *$ & & \\
\hline Índice agressividade & $-0,2786 *$ & $-0,1743^{*}$ & $-0,2912^{*}$ & 0,0822 & $-0,0385$ & \\
\hline Índice de ansiedade & $0,2358 *$ & $-0,0029$ & $0,1638 *$ & 0,0578 & $-0,0667$ & $-0,0888$ \\
\hline
\end{tabular}

* $p<0,05$

e recusar pedidos não se observou elevada freqüência de satisfação. Cabe salientar que essas situações também encontram-se entre aquelas que foram relatadas como incômodas por um número expressivo de sujeitos.

Os pais dos adolescentes foram classificados em quatro categorias de estilo parental obtendo-se os seguintes resultados na combinação dos escores dos pais e das mães: autoritativos $(33,2 \%)$, negligentes $(30,1 \%)$, autoritários $(12,4 \%)$ e indulgentes $(10,4 \%)$. Note-se que essas proporções seguem um padrão semelhante às distribuições observadas em outros estudos (Costa, Teixeira \& Gomes, 1998; Lamborn \& cols., 1991)

A Tabela 2 apresenta as correlações (Pearson) observadas entre as variáveis exigência e responsividade parentais (combinadas) e os índices de resposta adequada, ansiedade, agressividade, incômodo e satisfação.

Observou-se uma correlação significativa $(p<0,05)$ moderada e positiva entre exigência e responsividade parental, o que está de acordo com a literatura (Costa, Teixeira \& Gomes , 1998). De uma forma geral, as dimensões responsividade e exigência mostraram-se relacionadas às variáveis de interesse, à exceção da variável índice de resposta adequada. Note-se que o nível de ansiedade correlacionou-se significativamente apenas com o nível de exigência e não com o de responsividade. Cabe destacar também as correlações, ainda que pequenas, entre o índice de respostas adequadas e os índices de agressividade, ansiedade, incômodo e satisfação.

As diferenças entre os grupos de adolescentes com diferentes percepções de estilos parentais nos índices de adequação de respostas, ansiedade, agressividade, incômodo e satisfação foram verificadas através de uma análise de variância multivariada (MANOVA), tendo como variável

Tabela 3 - Resultados da análise de variância multivariada para as variáveis índices de resposta adequada, ansiedade, agressividade, incômodo e satisfação

\begin{tabular}{lccc}
\hline E feitos & $\mathbf{F}$ & $\mathbf{g}$ & $\mathbf{p}<$ \\
\hline Principal estilo parental & 2,23 & $(15 ; 480)$ & 0,01 \\
\hline Univariadas & & & \\
\hline Índice de comp. adequado & 0,98 & $(3 ; 162)$ & 0,41 \\
Índice de ansiedade & 3,57 & $(3 ; 162)$ & 0,02 \\
Índice de agressividade & 2,92 & $(3 ; 162)$ & 0,04 \\
Índice de incômodo & 2,72 & $(3 ; 162)$ & 0,05 \\
Índice de satisfação & 3,59 & $(3 ; 162)$ & 0,02 \\
\hline
\end{tabular}

independente o estilo parental (com quatro categorias: autoritativo, autoritário, indulgente e negligente) e variáveis dependentes os cinco índices referidos anteriormente. A Tabela 3 apresenta os resultados da MANOVA.

A MANOVA indicou diferenças significativas $(p<0,05)$ entre os grupos para as variáveis índice de ansiedade, agressividade, incômodo e satisfação. Desta forma, testes a posteriori foram realizados para detectar quais grupos diferiam entre si. A Tabela 4 apresenta as médias para as variáveis consideradas e os resultados das comparações entre os grupos.

Os dados da Tabela 4 nos mostram que não houve diferenças significativas entre os grupos no que diz respeito à variável índice de resposta adequada. Quanto ao nível de agressividade, o grupo autoritativo apresentou escores significativamente mais baixos que o negligente. Em relação ao índice de ansiedade, os adolescentes do grupo de estilo autoritativo obtiveram escore significativamente superior ao grupo indulgente, enquanto os do grupo autoritário apresentaram pontuação significativamente mais elevada que os grupos indulgente e negligente. No que diz respeito à variável índice de incômodo, o grupo autoritativo teve escore significativamente inferior aos dos grupos autoritário e negligente. Finalmente, o índice de satisfação observado para o grupo autoritativo foi significativamente superior ao do grupo de estilo parental negligente.

\section{Discussão}

As descrições do comportamento adequado mostraram que, de uma forma geral, os adolescentes relatam a emissão das habilidades sociais necessárias para as situações investigadas. Esse resultado está em concordância com outros trabalhos que investigam populações não clínicas (Del Prette, 1985). As situações onde ocorreram maiores freqüências de comportamentos inadequados foram as que investigaram as habilidades de iniciar relacionamento interpessoal, solicitar mudança no comportamento do outro e expressar sentimentos. É interessante observar que Hidalgo e Abarca (1994) já haviam alertado para o fato de que a habilidade que impõe maior dificuldade para o adolescente é a de estabelecer relações interpessoais. Possivelmente, essa deficiência ocorre porque uma das tarefas centrais desse período é o estabelecimento de relações independentes e em ambientes não familiares. Logo, nessa fase do desenvolvimento, o indivíduo 
Tabela 4 - Médias (e desvios-padrão) dos índices de resposta adequada, ansiedade, agressividade, incômodo e satisfação (e comparações entre grupos de estilo parental)

\begin{tabular}{|c|c|c|c|c|c|}
\hline & Autoritário (a) & Autoritativo (b) & Indulgente (c) & Negligente (d) & Dif. signif. entre grupos* \\
\hline Índice de comportamento adequado & $1,710(0,130)$ & $1,711(0,155)$ & $1,701(0,162)$ & $1,666(0,162)$ & \\
\hline Índice de agressividade & $0,050(0,066)$ & $0,034(0,065)$ & $0,070(0,073)$ & $0,072(0,089)$ & $b<>d$ \\
\hline Índice de ansiedade & $0,054(0,059)$ & $0,038(0,055)$ & $0,010(0,045)$ & $0,021(0,052)$ & $b<>c ; a<>c, d$ \\
\hline Índice de incômodo & $1,513(0,445)$ & $1,411(0,221)$ & $1,474(0,172)$ & $1,492(0,181)$ & $b<>a, d$ \\
\hline Índice de satisfação & $1,767(0,181)$ & $1,817(0,170)$ & $1,728(0,215)$ & $1,705(0,218)$ & $b<>d$ \\
\hline
\end{tabular}

* $\quad p<0,05$ (teste de menor diferença significativa)

está começando a aprender e a testar essa habilidade nas situações interpessoais.

A situação que investigou a habilidade de expressar opiniões diante dos pais foi referida como muito incômoda por aproximadamente $40 \%$ dos adolescentes. O incômodo relatado parece decorrer de mudanças especiais nas relações entre pais e filhos observadas na adolescência: os padrões relativamente unilaterais de autoridade são renegociados e transformados em padrões de mutualidade (Sobreira-Lopes, 1994). Nessa fase, o indivíduo está começando a questionar e discutir as posições paternas, impulsionando seus pais para o diálogo.

A presença de ansiedade nas situações foi investigada por sua importância para o desempenho do indivíduo em termos de habilidades sociais. A situação que parece gerar mais ansiedade é aquela que exige a habilidade de falar em público. Essa ansiedade não parece estar presente em função de uma deficiência nessa área, já que a maioria dos sujeitos relatou o comportamento adequado para lidar com a situação. Pode-se supor que a ansiedade que acompanha o comportamento adequado, nesse caso, seja consequiência do próprio enfrentamento da situação.

Durante a análise dos dados, chamou a atenção a forma agressiva com a qual alguns adolescentes relataram seu comportamento na situação investigada. Sendo assim, considerou-se a hipótese de que a ausência de um repertório adequado para lidar com a situação pudesse estar relacionado com a ocorrência do comportamento agressivo. As situações em que se observou maior frequiência de comportamento agressivo foram aquelas que investigaram as habilidades de defender os próprios direitos, de solicitar mudança no comportamento do outro e de expressar sentimentos. Essas duas últimas habilidades incluem-se entre as que apresentaram maior frequiência de comportamento inadequado. $\mathrm{O}$ comportamento agressivo pode estar ocorrendo, nesses casos, devido à ausência de alternativas no repertório comportamental do indivíduo.

O alto índice de satisfação com a resposta relatada poderia indicar que tanto a emissão quanto a não emissão da resposta adequada pode estar sendo positivamente avaliada pelos adolescentes (Del Prette, Del Prette \& Castelo Branco, 1992). No entanto, o teste Qui-quadrado $(p<0,05)$ indicou uma associação significativa entre o índice de comportamento adequado e o grau de satisfação na maioria das situações, com exceção da $\mathrm{E}$ (solicitar mudança no comportamento do outro) e G (recusar pedidos). Isso significa que quando o com- portamento descrito foi classificado como adequado, os adolescentes tendiam a relatar-se satisfeitos com sua resposta. Por outro lado, quando o comportamento foi classificado como inadequado, os adolescentes tendiam a relatar-se insatisfeitos com sua resposta. Esses dados sugerem que os adolescentes estão apresentando uma adequada percepção de seu desempenho social, estando conscientes do nível de adequação de seu comportamento. Além disso, é possível que o ambiente, ou seja, as pessoas que fazem parte do convívio dos adolescentes, esteja fornecendo a eles uma retroalimentação coerente com o comportamento apresentado.

A associação entre índice de comportamento adequado e o grau de satisfação não foi significativa nas situações E (solicitar mudança no comportamento do outro) e G (recusar pedidos). Na situação $\mathrm{E}$, que investiga habilidade de solicitar mudança no comportamento do outro, esse resultado foi encontrado possivelmente porque grande parte dos adolescentes achou que a melhor forma de diminuir a frequiência do comportamento desagradável era evitar o colega, não se dirigindo a ele e relatavam estar satisfeitos com essa estratégia. Quanto à situação G, que exige habilidade de recusar pedidos, a ausência de associação deve-se, provavelmente, ao fato de uma parte dos adolescentes ter relatado estar satisfeita com o uso de desculpas e mentiras para recusar o pedido. Esses adolescentes parecem possuir uma compreensão de "adequação social" em termos de evitar conflitos, mesmo que isso implique em omitir-se na afirmação dos próprios direitos e na busca de relações mais equilibradas (Del Prette, Del Prette \& Castelo Branco, 1992).

Os resultados encontrados com a utilização do teste de correlação aponta para alguns dados interessantes. A correlação positiva observada entre índice de ansiedade e índice de comportamento adequado, embora pequena, nos sugere que o simples enfrentamento de situações que requerem habilidades sociais é provocador de ansiedade para os adolescentes, ainda que seus comportamentos sejam em geral adequados. Além disso, o incômodo mostrou-se negativamente correlacionado à adequação das respostas, indicando que o sentimento desagradável pode ser decorrente de uma ausência de repertório comportamental para lidar com as situações.

A correlação positiva significativa entre a variável exigência e o índice ansiedade sugere que a exigência parental pode não favorecer o desenvolvimento de formas adequadas para lidar com situações interpessoais. Por outro lado, a dimensão responsividade aparece correlacionada negativamente aos 
índices de incômodo e agressividade, sugerindo que essa variável contribui para um melhor desempenho social. A correlação negativa encontrada entre índice de agressão e índice de comportamento adequado está de acordo com a hipótese apresentada anteriormente de que o comportamento agressivo surge como uma alternativa à falta de repertório para lidar com as situações interpessoais.

Ao contrário do esperado, não ocorreram diferenças significativas entre os grupos de adolescentes com diferentes percepções de estilos parentais (autoritário, autoritativo, negligente e indulgente) em relação ao índice de comportamento adequado. É provável que a não ocorrência de diferença significativa entre os grupos deva-se a outros fatores, como limites do instrumento utilizado para avaliar a variável habilidades sociais. Note-se que os grupos autoritativo e autoritário apresentaram médias mais elevadas para estas variáveis, indicando que apresentaram comportamentos mais adequados, em relação aos outros dois grupos. Esses resultados podem ser avaliados apenas como tendências, mas são concordantes com a literatura que indica que adolescentes de famílias desses dois estilos familiares apresentam melhor desempenho psicossocial.

Os resultados indicaram que há diferenças modestas, mas estatisticamente significativas e teoricamente adequadas, nas variáveis índice de agressividade, de ansiedade, de incômodo e de satisfação e os grupos de adolescentes. Os resultados dos grupos que identificaram seus pais como autoritativo e negligente estão de acordo com outros estudos (Lamborn, Mounts, Steinberg \& Dornbusch, 1991) que indicam um melhor ajustamento do primeiro grupo em relação ao segundo. Nesse sentido, os jovens do grupo autoritativo apresentaram menor índice de comportamentos agressivos, menor índice de incômodo nas situações investigadas e maior grau de satisfação com o próprio comportamento, sugerindo maior confiança em suas próprias habilidades e desempenho (Maccoby \& Martin, 1983). Por outro lado, o grupo negligente apresentou maiores níveis de comportamento agressivo e de incômodo com seu comportamento.

No caso específico da agressividade apresentada pelo grupo negligente, Bandura e Walters (1959) alertaram para o fato de que a falta de engajamento dos pais e a frustração que surge nos filhos pela falta de afeto e de uma atitude firme dos pais são condições importantes para a ocorrência do comportamento agressivo. Esses autores ressaltam que jovens agressivos tendem a ter mães ineficazes como agentes socializadores, colocando poucos limites no comportamento de seus filhos, fazendo menos cobrança por obediência e sendo menos consistentes em suas práticas. Tal descrição aproxima-se do estilo negligente e poderia ser considerada nesse caso.

A diferença significativa encontrada na variável grau de satisfação, entre os grupos de adolescentes que perceberam seus pais como autoritativo e negligente, sugere que filhos de pais autoritativos estão mais satisfeitos com seu comportamento. Tal fato parece ocorrer não somente por estes jovens serem mais habilidosos, mas por serem mais auto-confiantes e apresentarem uma percepção menos distorcida de seu desempenho social. Por outro lado, filhos de pais negligentes, segundo a literatura, não apresentam um parâmetro claro sobre quais padrões comportamentais são esperados e adequados, logo não estão muito aptos a realizar uma avaliação de seu próprio comportamento. Além disso, os estudos indicam que esses adolescentes apresentam um pior desempenho em muitas variáveis tais como competência e desempenho social.

Os grupos de adolescentes com pais autoritários e indulgentes, respectivamente, apresentaram resultados que merecem ser contrastados com os dois outros grupos. Os jovens de pais autoritários apresentaram-se significativamente mais ansiosos do que o grupo indulgente e negligente, e mais incomodados com as situações investigadas em relação ao grupo negligente. Os resultados sugerem que a dimensão exigência, que diferencia o estilo autoritário dos outros dois, esteja associada com indivíduos preocupados e inseguros quanto ao seu desempenho, mesmo apresentando repertório adequado. Esse conjunto de dados está de acordo com a afirmação de (Lamborn, Mounts, Steinberg \& Dornbusch, 1991) de que os jovens de famílias autoritárias apresentam prejuízos em termos de auto-confiança e de percepção de seu próprio comportamento social. A família identificada como autoritária dá ao adolescente a impressão de que o jovem não é capaz de realizar as tarefas de forma independente (Maccoby \& Martin, 1983).

Como foi discutido anteriormente, a exigência parental parece não favorecer o desempenho social adequado nos adolescentes. No entanto, os adolescentes que identificaram seus pais como autoritários e autoritativos apresentaram baixos níveis de comportamento agressivo, quando comparados aos adolescentes dos grupos negligente e indulgente. Esses dados sugerem que a supervisão e o controle (característicos da dimensão exigência, presente apenas nos dois primeiros estilos) podem, nesse caso, ajudar a deter o desenvolvimento de problemas de comportamento.

Os resultados encontrados nesse estudo, ainda que modestos, mostram a relevância do estudo de habilidades sociais relacionadas ao contexto do ambiente familiar, em particular no que se refere aos estilos parentais. Indicam, também, a necessidade de implementação de métodos para uma melhor investigação das variáveis familiares envolvidas no desenvolvimento do comportamento social na adolescência.

\section{Considerações Finais}

Esse estudo teve como objetivo investigar as relações entre os estilos parentais e o desenvolvimento de habilidades sociais na adolescência. Além disso, pretendeu investigar como os adolescentes de nível sócio-cultural médio e baixo comportam-se em termos de habilidades sociais. A maioria dos jovens relatou apresentar as habilidades necessárias para superar as situações interpessoais investigadas. Sendo assim, o interesse dos profissionais da área de saúde mental e dos educadores deve concentrar-se no estudo da pequena parcela que apresenta dificuldades para desempe- 
nhar-se socialmente. Para isso, é necessária a contínua investigação não só de tratamentos específicos, mas principalmente de programas preventivos que possam ser realizados com os próprios adolescentes ou com seus pais, que são os principais responsáveis pelo desenvolvimento global dos filhos.

O trabalho junto à população não clínica, afirma Del Prette (1985), traz contribuições como a implementação de programas de intervenção em nível de "profilaxia", podendo-se pensar em programas orientados para ajudar as pessoas a adquirir maior habilidade nas relações interpessoais, na procura de emprego, na verbalização de sentimentos, no trato com autoridades, nas situações afetivas e no exercício da cidadania. Um outro aspecto decorrente do trabalho com população não clínica seria o conhecimento sobre comportamentos considerados como adequados na resolução de problemas, na educação de crianças, nas situações interpessoais familiares ou sociais.

A interface entre o conceito de habilidades sociais e a psicologia do desenvolvimento ainda parece incipiente. Não foram encontrados trabalhos que tenham investigado o encaminhamento das deficiências em habilidades sociais, especialmente na adolescência, ao longo do desenvolvimento. Considerando que essas habilidades são aprendidas, parece razoável supor que algumas dificuldades (dependendo da gravidade e do tipo de habilidade em questão) possam ser superadas a partir da experiência e do treino em ambiente natural. Por exemplo, algumas dificuldades encontradas nesse estudo, como estabelecer relacionamento interpessoal ou com sexo oposto, referem-se a habilidades que estão começando a ser exigidas na adolescência, o que justificaria a deficiência. Pode-se supor que com o treino e as repetidas experiências as dificuldades sejam superadas, sem a necessidade de uma intervenção.

As relações encontradas entre os estilos parentais e as variáveis relacionadas às habilidades sociais são importantes, pois indicam as práticas parentais que estão relacionadas ao adequado ou efetivo desenvolvimento de comportamentos sociais na adolescência. Esses resultados, juntamente com outros estudos, podem subsidiar a iniciativa de programas de treinamento para pais e a prevenção de distúrbios psicossociais nos adolescentes, relacionados à deficiência no domínio das habilidades sociais.

Cabe salientar que um ponto crítico em relação ao estudo das habilidades sociais refere-se à sua avaliação, já que não existem instrumentos adequados para esse fim (Hidalgo \& Abarca, 1994). Dessa forma, os resultados estatísticos anteriormente discutidos devem ser observados com reserva, devido às limitações do instrumento utilizado. Sugere-se a implementação de instrumentos que avaliem as habilidades sociais, bem como as variáveis associadas que podem alterar a forma do comportamento, como ansiedade e agressividade. Ademais, a combinação entre trabalhos quantitativos e qualitativos é uma opção adequada e interessante para o aprofundamento de estudo sobre a relação entre contexto familiar e desempenho social.

\section{Referências}

Amaral, V.L., Bravo, M. \& Messias, M.C. (1996). Desenvolvimento de habilidades sociais em adolescentes portadores de deformidades faciais. Estudos de Psicologia,13, 31-47.

Arón, A. \& Milicic, N. (1994). Viver com os outros: programa de desenvolvimento de habilidades sociais. (J. Santos, Trad.) Campinas: Editoral Psy II.

Bandura, A. \& Walters, R. (1959). Adolescent agression. New York: The Ronald Press Company.

Baumrind, D. (1966). Effects of authoritative parental control on child behavior. Child Development, 37, 887-907.

Caballo, V. (1993). Manual de evaluación y entrenamiento de las habilidades sociales. Madrid: Siglo Veintuino Editores.

Chioqueta, A. (1998). Adaptação para o português do inventário de depressão estado-traço: fidedignidade e validade. Dissertação de Mestrado, Universidade Federal do Rio Grande do Sul, Porto Alegre.

Costa, F., Teixeira, M.A. \& Gomes, W. (1998). Construção de um instrumento de avaliação de estilos parentais: uma continuação [Resumo]. Em Sociedade Brasileira de Psicologia (Org.), Resumos de comunicação científica, XXVIII Reunião Anual de Psicologia (p. 127). Ribeirão Preto: SBP

Del Prette, A. (1985). Treinamento comportamental: uma alternativa de atendimento à população não clínica. Revista de Psicologia Fortaleza, 3, 67-81.

Del Prette, A., Del Prette, Z.A.P. \& Castelo Branco, U.V. (1992). Competência social na formação do psicólogo. Paidéia: $\mathrm{Ca}$ dernos de Educação, 2, 40-50.

Del Prette, A., Del Prette, Z.A.P., Torres, A. \& Pontes, A. (1998). Efeitos de uma intervenção sobre a topografia das habilidades sociais de professores. Psicologia Escolar e Educacional, 2 , $11-22$.

Dornbusch, S., Ritter, P., Leiderman, P., Roberts, D. \& Fraleigh, M. (1987). The relation of parenting style to adolescent school performance. Child Development, 58, 1244-1257.

Garcia, F. \& Del Prette, Z.A. (1998). Um programa de habilidades sociais para adolescentes de bom desempenho acadêmico [Resumo]. Em Sociedade Brasileira de Psicologia (Org.), Resumos de comunicação científica, XXVIII Reunião Anual de Psicologia (p. 155). Ribeirão Preto: SBP.

Glasgow, K., Dornbusch, S., Troyer, L., Steinberg, L. \& Ritter, P. (1997). Parenting styles, adolescents' attributions and educational outcomes in nine heterogeneus high schools. Child Development, 68, 507-529.

Guarch, C. (1994). Evaluación de las habilidades sociales. Em R. Fernandez-Ballesteros (Org.), Evaluación conductual hoy: Um enfoque para el cambio en psicologia clínica e de la salud (pp. 347-383). Madrid: Pirámide S.A.

Hennigen, I. (1994). Dimensões psicossociais da adolescência: identidade, relação familiar e relação com amigos. Dissertação de Mestrado, Universidade Federal do Rio Grande do Sul, Porto Alegre. 
Hidalgo, C. \& Abarca, N. (1994). Programa de entrenamiento en habilidades sociales. Santiago: Ediciones Universidad Católica de Chile.

Kaplan, H. \& Sadock, B. (1993). Compêndio de psiquiatria. (D. Batista, Trad.) Porto Alegre: Editora Artes Médicas. (Trabalho original publicado em 1991)

Lamborn, S., Mounts, N., Steinberg, L. \& Dornbusch, S. (1991). Patterns of competence and adjustment among adolescents from authoritative, authoritarian, indulgent and neglectful families. Child Development, 62, 1049-1065.

Levenson, R. \& Gottman, J. (1978). Toward the assessment of social competence. Journal of Consulting and Clinical Pychology, $46,453-462$.

Lewis, M. \& Wolkmar, F. (1993). Aspectos clínicos do desenvolvimento na infância e adolescência. (G. Giacomet, Trad.) Porto Alegre: Artes Médicas. (Trabalho original publicado em 1990)

Maccoby, E. \& Martin, J. (1983). Socialization in the context of the family: Parent-child interaction. Em P.H. Mussen \& E. Hetherington (Orgs.), Handbook of child psychology: Socialization, personality and social development (pp.1-101). New York: Wiley.

McFall, R. (1982). A review and reformulation of the concept of social skills. Behavioral Assessment, 4, 1-33.

Rimm, D. \& Masters, J. (1983). Terapia comportamental: técnicas e resultados experimentais. (A. Alves, Trad.) São Paulo: Editora Manole Ltda.
Rojas, R. (1995). Habilidades sociales: psicoterapia grupal con pacientes esquizofrenicos cronicos. Revista de Psicologia de la PUCP, 8, 63-95.

Sarason, I. \& Sarason, B. (1981). Teaching cognitive and social skills to high school students. Journal of Consulting and Clinical Psychology, 49, 908-918.

Silva, A. \& Del Prette, A. (1998). Treinamento de habilidades sociais no promoção de interações positivas entre pais e filhos [Resumo]. Em Sociedade Brasileira de Psicologia (Org.), Resumos de comunicação científica, XXVIII Reunião Anual de Psicologia (p. 256). Ribeirão Preto: SBP.

Sobreira-Lopes, R.C. (1994). O contexto familiar no desenvolvimento da autonomia e da moralidade na adolescência. Psicologia: Reflexão e Crítica, 7, 59-74.

Steinberg, L, Elmen, J. \& Mounts, N. (1989). Authoritative parenting, psychosocialmaturity and academic success among adolescents. Child Development, 60, 1424-1436.

Trower, P. (1995). Adult social skills: State of art and future directions. Em W. O’Donohue \& L. Krasner (Orgs.), Handbook of psychological skills training: Clinical techniques and applications (pp. 54-80). New York: Allyn and Bacon.

Wagner, A., Flacke, D. \& Meza, E. (1997). Crenças e valores dos adolescentes acerca da família, casamento, separação e projetos de vida. Psicologia: Reflexão e Crítica, 10, 155-168. 